\title{
Eosinophilic Granuloma of the Middle Ear
}

SHIGEHARU UEKI, MD, PhD, Department of Infection, Allergy, Clinical Immunology and Laboratory Medicine, Akita University Graduate School of Medicine, Akita; HIROYUKI YAMAUCHI, MD, PhD, Yamauchi ENT Clinic, Odate; MASAHIDE TAKEDA, MD, PhD; JUNICHI CHIHARA, MD, PhD, Department of Infection, Allergy, Clinical Immunology and Laboratory Medicine, Akita University Graduate School of Medicine, 1-1-1, Hondo,

Akita 010-8543, Japan. Address correspondence to Dr. Ueki; E-mail: ueki-shige@nify.com. J Rheumatol 2011;38:2005-6; doi:10.3899/jrheum.110126

A 33-year-old woman with a 10-year history of Churg-Strauss syndrome (CSS) was referred to an otolaryngologist for subjective bilateral ear discharge. Examination of the ear dis- charge demonstrated heavy content of eosinophils with no significant microorganisms, including fungi, and otoendoscopy showed large masses protruding from bilateral middle ears
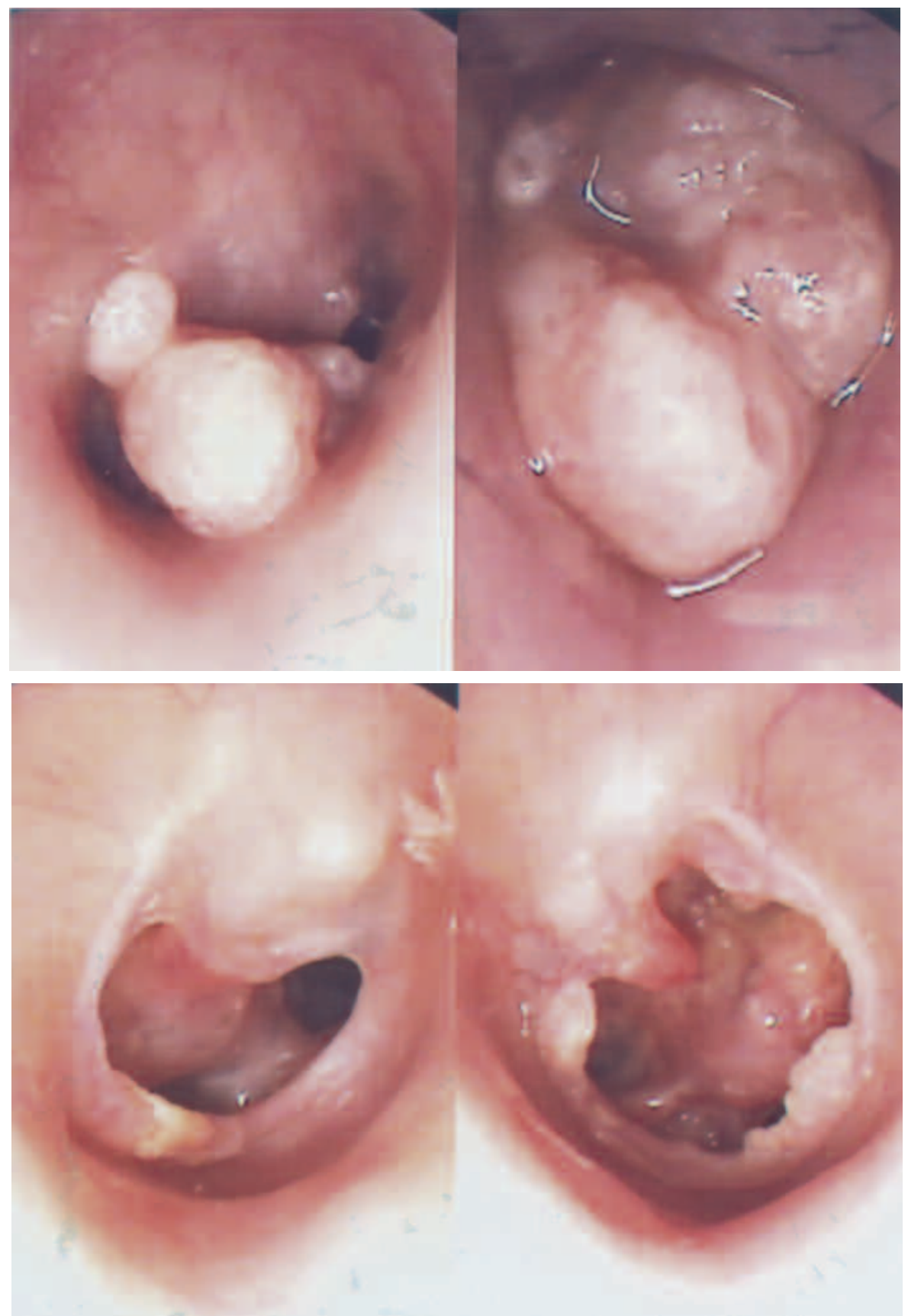

Figure 1. Otoendoscopic images of large masses protruding from middle ears on admission. The patient was initially treated with local injection of triamcinolone with continuation of previous oral corticosteroid regimen $(30 \mathrm{mg} /$ day). Because the effect was insufficient, carbon dioxide laser vaporization was performed every few weeks.

Figure 2. After 15 months of treatment, the size of the granuloma decreased and the tympanic membranes regenerated. 
(Figure 1). Her audiogram revealed moderate conductive hearing loss.

She had vasculitis of skin and lung infiltration at the time of the initial diagnosis with CSS, but no signs of vasculitis were noted by previous physicians during at least 8 years of continuous oral prednisolone treatment ( 7.5 to $30 \mathrm{mg} /$ day $)$. Attempts to further taper oral corticosteroids failed because of recurrent asthmatic symptoms. On admission, she was negative for antineutrophil cytoplasmic autoantibodies and was treated with inhaled corticosteroid, theophylline, and oral prednisolone $30 \mathrm{mg} /$ day. Fifteen months of treatment with local injection of triamcinolone and laser vaporization actively decreased the masses (Figure 2).

Although rhinitis and/or sinusitis are common in $\mathrm{CSS}^{1}$, the frequency of otological manifestations is not well known. Some patients progressed to sensorineural hearing loss or to otomastoiditis, even to bone destruction ${ }^{2,3}$. Ishiyama and
Canalis have reported the retrospective review of 5 cases with otological manifestations in the later stage of $\mathrm{CSS}^{3}$. All of them were highly responsive to systemic steroids, and successively maintained with low doses of oral prednisone (4 to 10 mg daily or every other day). In contrast, the flare in this patient was during the years of continuous corticosteroid treatment, suggesting a greater disease activity in the ear.

\section{REFERENCES}

1. Bacciu A, Bacciu S, Mercante G, Ingegnoli F, Grasselli C, Vaglio A, et al. Ear, nose and throat manifestations of Churg-Strauss syndrome. Acta Otolaryngol 2006;126:503-9.

2. Watanabe R, Ishii T, Harigae H. Churg-Strauss syndrome with exophthalmos and orbital bone destruction. Intern Med 2010;49:1463-4.

3. Ishiyama A, Canalis RF. Otological manifestations of Churg-Strauss syndrome. Laryngoscope 2001;111:1619-24. 